\title{
REPLACING HUMAN RESOURCES WITH ARTIFICIAL INTELLIGENCE - ACCEPTANCE OR DENIAL?
}

\author{
Neluta CURUia (BARBUlESCU), \\ Mihaela CiOREI (STOIAN), \& Florina CHISCOP
}

\begin{abstract}
Artificial intelligence is a rapidly evolving phenomenon that is fully supported by private companies throughout development. Objectives such as success, efficiency, productivity and economy are some starting points in achieving this great goal. What is interesting and very serious to consider is the impact that artificial intelligence will have on human normality. Private companies are preparing their people for such a technology, but public institutions do not have such a change on the list of priorities, which must be treated very carefully, such a change cannot affect only a part of us, we cannot isolate or live in two parallel worlds. Measures such as training of all employees and implementation of various applications to facilitate their activities and even the starting point for accepting robot colleagues, will people accept or deny a future transformation?
\end{abstract}

Key words: artificial intelligence, robots, evolution, acceptance, denial
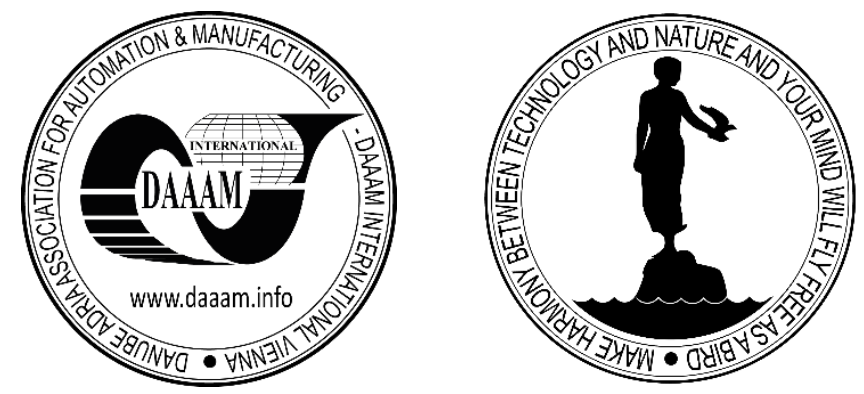

Authors' data: Curuia, N[eluta]; Stoian, M[ihaela]; \& Chiscop F[lorina], University Politehnica of Bucharest Splaiul Independenței 313, 60042 Bucharest, RO, Nelutacuruia@gmail.com, mihaela.stoian333@gmail.com

This Publication has to be referred as: Curuia, N[eluta]; Stoian, M[ihaela] \& Chiscop, F[lorina] (2019). Replacing Human Resources with Artificial Intelligence Acceptance or Denial?, Chapter 23 in DAAAM International Scientific Book 2019, pp.277-286, B. Katalinic (Ed.), Published by DAAAM International, ISBN 978-3902734-24-2, ISSN 1726-9687, Vienna, Austria

DOI: $10.2507 /$ daaam.scibook.2019.23 
Curuia, N.; Stoian, M. \& Chiscop, F.: Replacing Human Resources with Artificial I...

\section{Introduction}

Artificial intelligence is no longer an SF story but a reality that is evolving more and more as the day passes. It has gained notoriety in most all fields of activity, producing substantial changes in the individual's view on this subject.

At present we are witnessing so many changing situations that maybe due to the routine in which we are engaged daily, we either fail to realize them or we simply do not attach importance.

From the very beginning man wanted the activities that he carries out to be facilitated by various tools or working techniques and throughout the evolution we come to this phenomenon of artificial intelligence, which is currently debated only at the level of private organizations. directly to everyone. The effects of artificial intelligence divide people into two categories, those who are for and those who are against, as realistic and debatable as possible because its benefits are exposed so dangerous actions can be out of control.

It is well known that at the level of private companies, annually, quite large percentages of the budget are directed towards the development of artificial intelligence, because they all want to benefit from the benefits of its development, becoming more efficient, more productive.

In this digital manufacturing oriented new approach, simulations will be used extensively in specific plant operations [1]. The digital twin of the manufacturing or processing architecture will become a part of the manufacturing plant design [2]. This digital twining will provide a diagnose of the system performances in different manufacturing scenarios based on simulations including machines, products, and humans [3].

In this paradigm, operators test and optimize the machine settings during the manufacturing process in the virtual world, thereby driving down machine setup times. Manufacturer's sensors and machines are networked and make use of embedded computing using the digital twining in order to introduce changes in the manufacturing scenarios [4]. All structural elements of the manufacturing architectures are enriched with embedded computing and connected to communicate and interact both with one another and with centralized controllers, as necessary [5].

Products are identified by radio frequency codes, and workstations are informed about the manufacturing steps that must be performed for each product to perform the specific operation. Transforming manufacturing devices in smart products requires a rethinking of design. Becoming intelligent, connected devices, which are increasingly embedded in broader systems, manufacturing devices radically reshape industrial engineering.

Manufacturing goes beyond production of the physical object, because operating a smart, connected manufacturing device requires a supporting cloud-based system [6]. The digital twin of the manufacturing architecture is related with all the abovementioned technologies used in this paradigm. 


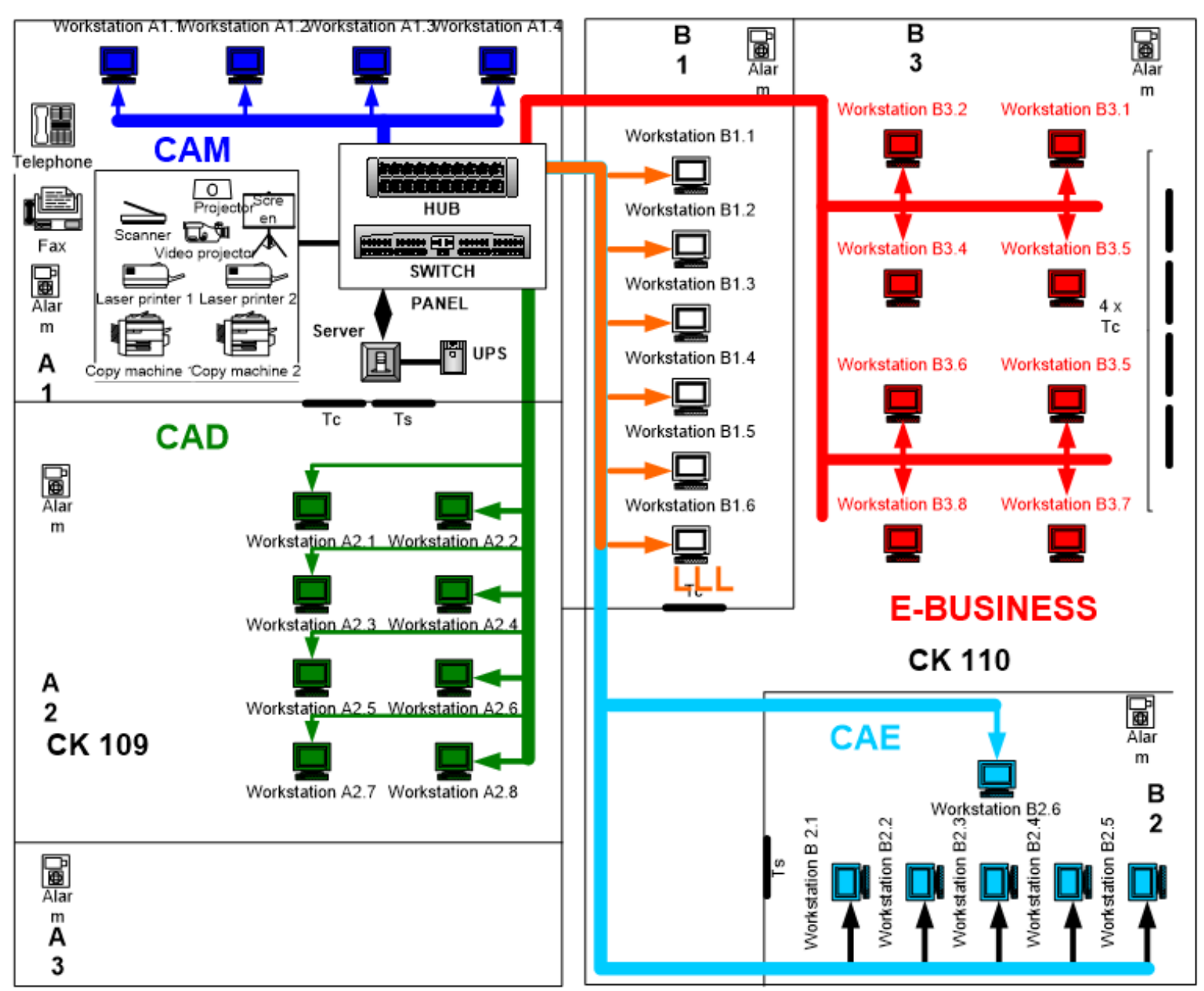

Fig. 1. The PREMINV training research and consulting experimental platform

Cooperative processes are not the automatic results of implementing collaborative, real-time communication technologies, but the result of a carefully designed and systematically maintained virtual team development plan. We included the digital twin presented above in an experimental platform for training, research and consulting in the new digital economy, located in the UPB-PREMINV centre from University "POLITEHNICA" of Bucharest. We started to develop this platform years ago [7], and now we updated it to meet the smart industry requirements.

We consider that for business, e-service is going to be a new way to save money, to revenue growth, and faster development model. For end-users, e-services increase productivity and simplify life, take advantage of more sophisticated and specialized services on as needed basis.

\section{Robots vs. Human Resources}

Probably we all wonder to what extent robots will replace human resources and whether this will have a more pronounced emphasis on professional life or why not in personal life. 
There are a lot of predictions about the invasion of personal space by robots starting from the facilitation of domestic activities until the acquisition of a life partner, so we cannot limit ourselves or worry only about what might change professionally. Artificial intelligence is indeed the cornerstone of a new world that is easy, it will easily be shaped by every step taken in discovering new information or solutions that will be integrated into human existence.

The information we receive or that are open to public access is of course a result of the results or tests carried out by experts, but as individuals we can do one thing that robots cannot do for now, that is, to guess to what extent the future changes. they will affect us.

As several scientific researchers claim that artificial intelligence refers to systems or machines that mimic human intelligence to perform certain activities more efficiently and more quickly, I will not insist on this meaning explained above but will summarize more. [8] about the assumptions or situations, we will face when artificial intelligence is part of our daily life. We agree here that artificial intelligence (AI) refers to systems or machines that mimic human intelligence, to perform various activities and which can be iteratively improved based on the information that is collected by the form defined by Oracle Artificial Intelligence.

From my point of view, artificial intelligence is a kind of baby that needs to go through all the stages to reach maturity and show its ability, which is not a sure thing. In all the stages passed, the result can be one that would lead the global population to a fantastic standard of living or destroy it, an aspect that I do not conclude for the first time, are people who, from the perspective of their activities, can issue a diagnosis as close as possible to truth.

\section{Artificial intelligence is an extraordinary thing, beneficial, innovative but so sensitive}

There are a lot of questions that I, a noted individual, ask myself when I imagine a world where living with robots will be normal. If these babies who will grow and evolve by learning human learning will reach a level at which people can never reach how we can compete with such situations, how can we compete with their speed of orientation, calculation, efficiency? I think the only thing we can rely on is the fact that emotions cannot be learned, this differentiates us and gives us hope that we will maintain a balance in terms of integrating this form of intelligence into our lives.

I will briefly address the advantages and disadvantages of this intelligence, summarizing myself strictly in my opinion. There are areas where if people were to be replaced with robots the discoveries would be fabulous because of their abilities, discoveries that would be long delayed due to the limited ability of people, not to forget that it is the human factor that prevents us from being connected non-stop on a project, the fact that physiological needs such as food, rest or health problems are an impediment compared to a robot that enjoys a much greater freedom to act and give results. 
Areas such as medicine where robots could revolutionize current techniques or studies would give people greater hope in life by temporarily detecting diseases or even by finding remedies against incurable diseases. Medicine was a trivial example, the phenomenon of artificial intelligence can be applied in all areas, I am convinced that in the first phase its help would create a comfort and safety different from what exists today. The benefits would be many and probably only by testing on our own skin we could draw conclusions.

The less pleasant part and quite a lot of question marks is what would happen if this wonderful form of intelligence would get out of control, if through all the acquired knowledge it somehow contradicts its own vision of humanity that does not coincide with what we want we induce them. Honestly, I do not want to find out, but all I can say based on those studied and reported above is that somewhere a balance and control must be maintained, there is in my opinion a very fragile border between well-being and chaos, depends on we as wise people will choose or manage.

As I said above, private companies invest a lot in the development of artificial intelligence, each for different reasons, in principle financial. To develop, to evolve is a thing to be admired, the contact of the people working in the private environment with this form of intelligence, in one form or another, is a beneficial thing because the changes will come and we must be prepared for they.

All these investments in the private environment help to develop not only on the part of the economy, although this is the purpose in my opinion, but it helps to facilitate the development of the various activities that take a long time, is routine and the human resources used can be redistributed to other tasks. The fact that it is desired to replace human resources with robots in certain situations is an extraordinary thing, there are useless jobs and this chance to change the situation and for our benefit is clearly an advantage, but for us who have access to information, we are at current with the new trends, we study, we exchange experiences in different circumstances, all of these may seem normal but the changes that will occur will be negatively felt by another class of people, and do not say this thinking bad about other people.

I believe that there are no classes, but the society is careful to contradict us and we may unconsciously collaborate with us in publishing many social norms because we are the society. A lot of jobs will disappear and the impact of the product will have to be managed in a way and somehow early because we mentioned above, we are people and we have emotions, so those people will have to be redirected to other jobs, they will try a professional reorientation in my opinion.

In the next period, that will be measured in years or many years, there will be a way by which the Turing test (English mathematician Alan Turing imagined the test that bears his name and, once satisfied with a car, would prove his "intelligence" through "imitation game") will be passed without any problem, the cars will be able to think eventually and all their skills will have to learn to we use them for our benefit. There are so many hypothetical questions and situations that are in the field of science fiction that I am amazed that there is a very high probability of becoming a reality. [9] Artificial intelligence is such a complex subject and although there is plenty of information, assumptions, predictions, there is still a dose of mystery to many aspects. 
After trying to reach quite a few notions and aspects that I considered important, I found that the focus is on robots very strong in the private environment and it is normal, we all know what it means financing, and all kinds of needs that need to be covered in a developing project that must give us results.

Artificial intelligence and robots are not just the private system, the economy is not just the private system, it is true that this is the giant and from here everything started but the changes will not only affect the private domain, events that the implementation of artificial intelligence among people affects the entire population. [10] Global, perhaps this change will occur in some areas slower and in others more accelerated, depending on the level of training of people.

In the private domain I am sure that people will interact very often with this phenomenon and will be updated with absolutely all the changes but this whole process does not stop here.

The public system in my opinion is worrying about the transformation that will follow, because in addition to the fact that in terms of digitization they have lost the fight, they use quite a few rudimentary methods I could say and now I do not refer to a particular institution and to the majority. with whom we interacted over time.

Everything that means a public institution means outdated and it is not because of the employees, not even the management at the level of the institution, in which case the decisions are taken as it is known according to other criteria or priorities.

For the change to take place at the state level, for example, both private and public, it is necessary to standardize information and access to information, it is necessary that the workers reach a level of understanding and assimilation of all the events that will take place.

If this tacit denial of evolution persists, we will wake up living in two parallel worlds that can cause chaos. The fact that from the desire to find out how the employees of a public institution would react if they were put in the situation of being replaced by robots, I asked for the opinion in the first phase at the manager's level, thinking that solutions or methods of implementation can be found. of information of a nature to prepare employees.

I think people are totally unprepared for the subject of artificial intelligence, not to say that they refuse to believe in such a change.

The feedback received me in the situation of analysing very carefully the evolution of a phenomenon like the introduction of robots among employees, if at the level of managers the reactions were so repulsive I do not want to think about what happens among employees who influence in turn their other people based on the received reactions that do not have a beneficial effect but rather distort the reality, reject it.

What I want to emphasize through the related ones is that people are not trained and here I do not want to refer to a certain age category for example, but it is strange that an atmosphere or a better thought, from a certain one work place manages to indoctrinate people, so that they reject whatever is foreign, new, innovative or otherwise.

It is very important to realize that these people need to recover their lost time, missing information, accommodating with new trends in technology or better said new needs. [11] 
Strange is the fact that people actually look at everything from the beginning as something harmful but not something that facilitates the development of activities, but most likely it is about thinking and the fact that the trainings are completely lacking, a close relationship is maintained only with the issues that I keep strictly the execution of activities at the workplace.

It is true that decisions in everything regarding the public system are taken centrally and I strongly believe that disinterest is the main factor that maintains a certain atmosphere that can be controlled even through the lack of information.

Let us not forget that if one wants, one can, that is why I think that if a series of measures were made that would facilitate the improvement and study so that it would be productive, people would understand and adapt to the new requirements such as:

- training in the first phase at the level of managers, so that they understand the employees and support them, to embrace an idea that may be more efficient than the methods used;

- a survey at the institution or service level where employees would come up with ideas for optimizing their activities and together they could determine where there is a need for human resources, where they can be robots, of course at the proposal level, but these things can help enormous in the transformation of the institution;

- training with all employees to implement this system and explain that it is a beneficial and productive thing;

- solving the cases in which some of the staff will be replaced by robots and will have to be redistributed in other activities;

- in some cases a psychologist can be involved, who can help the employees in case of necessity, these changes, however normal they seem in the eyes of some, may seem very strange in the eyes of others, not to forget that for some people routine means safety and for some people may be affected by an imbalance, as we said we have emotions, it is quite difficult to manage sometimes.

I believe that if these measures were in place and considered by those who will start the process of change, it would greatly help the employees. The most efficient solution I think is that everything is gradual and well organized.

As an overview it is quite difficult to handle such situations, I cannot for the moment decide whether I personally think that artificial intelligence is a good thing or a bad one, but looking around I think that the optimizations that can be made would facilitate us comfort, existence.

Clearly, besides the measures mentioned above, I think that at the level of the public institution there is a need for change depending on the specifics of each, I think that various applications could be implemented, for example creating a common database in which each individual would have a profile with an updated description at a certain time, a profile that could help several institutions to collect data needed for the various formalities, for example in case of changing a document or in case of changing certain legal terms regarding citizens in the database, in this otherwise it 
would no longer intend to provide data or solve problems (for example: ANAF, ANI or MORE). It would be an extraordinary thing to create such a database because we know with all the bureaucratic activities and for how long I suppose, the problem could be posed in such a way that people do not feel that they are invading the personal space in the process of establishing such a database. bases, to become a reality it requires a lot of work but also understanding from the citizens.

It is relatively the way they will react but during such a process that will take time but the result I think is worth all the effort and patience dedicated.

In addition to various applications that can facilitate our existence and safety, robots could perform tasks of such a nature as to provide us with assistance in everything we do daily.

How things will evolve or be implemented depends on many factors, but I think that what we can achieve in the situation where robots will be part of our lives is to keep a constant, when we give them power to implement them. that everything is mutual, they offer us speed and efficiency, but we offer them emotions, feelings.

As much as people are reluctant about this phenomenon of artificial intelligence, we can reflect on its benefits. We can take a trivial example, a situation that we have all observed, namely the social networks. [12]

Each one of us is part of a generation that comes to life with its own indoctrination related to what surrounds us, as such trends where information flows very quickly people no longer feel the need to be next to each other, the virtual environment catches everyone's attention, and here I am I mean absolutely all the stages of age. If the fact that social networks have created this addiction in a relatively short time and maybe we cannot imagine how we would react if it did not work, I think we can do an exercise of imagination vis-à-vis robots.

It is possible that this reluctance becomes an addiction and people are attracted to the virtual world because they can create it as they wish to show, maybe they will prefer to stay in a world where it is not necessary to accept people whom they do not like it but they are needed, maybe this virtual world created with the help of artificial intelligence will represent for many individuals a true refuge.

\section{Conclusion}

So, I think that until the realization of this phenomenon there will be pros and cons, but we as people have to discover those fragile connections that could be created from the desire to evolve, links that we have to take care of. I believe that if we can be able to discern the advantages and disadvantages of each stage in which artificial intelligence will be found without leaving us driven by the thirst for greatness, we could find the solution of maintaining a balance and safety. Let us not forget that things are not always what they seem to be, and we must take into account at the moment of decision both the extraordinary and the danger.

I believe that balance, complacency, serious and careful analysis and empathy are the keys to helping change can be beneficial for people. Based on these considerations we established our main further research direction as follows: 
- Improving manufacturing architectures performances by developing new measuring tools based on modelling the system digital twin.

- Integrating CAM and material flow simulations in digital twins for collaborative networks.

- Integrating the investment analysis in the digital twins.

- Integrating engineering knowledge in material flow design.

- Integrating MFM with ERP (Enterprise Resource Planning) applications.

Current needs and practice in industrial engineering determined us to develop specific algorithms for diagnosis and optimization for manufacturing architectures using digital twining.

As can be noticed, our approach, although restrictive to industrial projects, can be however used to accommodate the advances in digital fabrication and the development of new manufacturing processes/technologies, thus responding to the current trend of industry.

\section{Acknowledgments}

This work has been funded by University POLITEHNICA of Bucharest, through the "GNAC ARUT Program". Identifier: UPB-GNAC ARUT Program-2018 Research project title: IOT platform material flow management in industry 4.0, Contract number: $162 / 01.10 .2018$.

\section{References}

Popescu, C A; Popa, C L; Cotet, C E \& Enciu, G (2016). Using Virtual Modelling for AS/RS Material Flow Management, Proceedings of the 27th DAAAM International Symposium, pp.0180-0186, Published by DAAAM International, ISBN 978-3902734-08-2, ISSN 1726-9679, Vienna, Austria, DOI: 10.2507/27th.daaam.proceedings.027

Wang, S., Wan, J., Li, D., \& Zhang, C. (2016). Implementing smart factory of industrie 4.0: An outlook. International Journal of Distributed Sensor Networks, pp. 1-10, ISSN: 15501477

Ayadi, M., Costa Affonso, R., Cheutet, V., Masmoudi, F., Riviere, A. \& Haddar, M. (2013). Conceptual model for management of digital factory simulation information, International Journal of Simulation Modelling, 2 (12), 107-119, ISSN 1726-4529.

O’Donovan, P., Leahy, K., Bruton, K. \& O’Sullivan, D. T. J. (2015). An industrial big data pipeline for data-driven analytics maintenance applications in large-scale smart manufacturing facilities, Journal of Big Data, pp 1-26, ISSN 2196-1115

Abdulrahman, W. (2014). Overview on Industrial Vision Systems, International Journal of Engineering Research \& Technology, Vol. 3, Issue 5, 2014, pp. 383-386, ISSN: 2278-0181. 
Curuia, N.; Stoian, M. \& Chiscop, F.: Replacing Human Resources with Artificial I...

Porter M.E., Heppelmann J.E. (2015) How Smart, Connected Products Are Transforming Companies, Harvard Business Review, October 2015, 1-19, HBR.org Dragoi G., Draghici A., Rosu S.M., Cotet C.E. (2009). Virtual Enterprise Network Solutions for Virtual Product Development in the SMEs. Proceedings of the CENTERIS'2009 - Conference on ENTERprise Information Systems, 7-9th October, Ofir, Portugal, ISSN 978-972-669-929-6, pp. 613-628.

press-https://www.oracle.com/ro/artificial-intelligence/what-is-artificialintelligence.html press-.https://www.cs.cmu.edu/ mihaib/articole/ai/ai-html.html press-.https://www.stiintaonline.ro/inteligenta-artificiala-ce-este-si-cum-functioneaza/ press -http://www.ziare.com/internet-si-tehnologie/tehnologie/10-previziuni-facutede-un-expert-in-inteligenta-artificiala-lumea-va-fi-de-nerecunoscut-in-2050-1478647 press -https://www.go4it.ro/inteligenta-artificiala/cat-de-periculoasa-este-inteligentaartificiala-de-ce-bill-gates-stephen-hawking-si-elon-musk-se-tem-de-tehnologia-incare-marile-companii-investesc-masiv-16237531/ 